\title{
(6) OPEN ACCESS \\ Comparing the effects of tofacitinib, methotrexate and the combination, on bone marrow oedema, synovitis and bone erosion in methotrexate-naive, early active rheumatoid arthritis: results of an exploratory randomised MRI study incorporating semiquantitative and quantitative techniques
}

Philip G Conaghan, ${ }^{1}$ Mikkel Østergaard, ${ }^{2}$ Michael A Bowes, ${ }^{3}$ Chunying Wu, ${ }^{4}$ Thomas Fuerst, ${ }^{4}$ Désirée van der Heijde, ${ }^{5}$ Fedra Irazoque-Palazuelos, ${ }^{6}$ Oscar Soto-Raices, ${ }^{7}$ Pawel Hrycaj, ${ }^{8}$ Zhiyong Xie, ${ }^{9}$ Richard Zhang, ${ }^{9}$ Bradley T Wyman, ${ }^{9}$ John D Bradley, ${ }^{9}$ Koshika Soma, ${ }^{9}$ Bethanie Wilkinson ${ }^{9}$

\begin{abstract}
Handling editor Tore K Kvien
- Additional material is published online only. To view please visit the journal online (http://dx.doi.org/10.1136/ annrheumdis-2015-208267)

For numbered affiliations see end of article.

\section{Correspondence to} Dr Philip G Conaghan, Leeds Institute of Rheumatic and Musculoskeletal Medicine, Chapel Allerton Hospital, Chapeltown Road, Leeds LS7 4SA, UK; p.conaghan@leeds.ac.uk
\end{abstract}

Received 17 July 2015 Revised 1 December 2015 Accepted 31 December 2015 Published Online First 25 January 2016

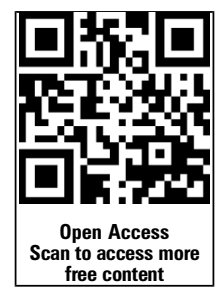

CrossMark

To cite: Conaghan $\mathrm{PG}$ Østergaard M, Bowes MA, et al. Ann Rheum Dis 2016;75:1024-1033.

\section{ABSTRACT}

Objectives To explore the effects of tofacitinib_-an oral Janus kinase inhibitor for the treatment of rheumatoid arthritis (RA) - with or without methotrexate (MTX), on MRI endpoints in MTX-naive adult patients with early active RA and synovitis in an index wrist or hand.

Methods In this exploratory, phase 2, randomised, double-blind, parallel-group study, patients received tofacitinib $10 \mathrm{mg}$ twice daily + MTX, tofacitinib $10 \mathrm{mg}$ twice daily + placebo (tofacitinib monotherapy), or MTX + placebo (MTX monotherapy), for 1 year. MRI endpoints (Outcome Measures in Rheumatology Clinical Trials RA MRI score (RAMRIS), quantitative RAMRIS (RAMRIQ) and dynamic contrast-enhanced (DCE) MRI) were assessed using a mixed-effect model for repeated measures. Treatment differences with $\mathrm{p}<0.05$ (vs MTX monotherapy) were considered significant.

Results In total, 109 patients were randomised and treated. Treatment differences in RAMRIS bone marrow oedema (BME) at month 6 were $-1.55(90 \% \mathrm{Cl}-2.52$ to -0.58$)$ for tofacitinib + MTX and $-1.74(-2.72$ to -0.76 ) for tofacitinib monotherapy (both $p<0.01$ vs MTX monotherapy). Numerical improvements in RAMRIS synovitis at month 3 were $-0.63(-1.58$ to 0.31$)$ for tofacitinib + MTX and $-0.52(-1.46$ to 0.41$)$ for tofacitinib monotherapy (both $\mathrm{p}>0.05$ vs MTX monotherapy). Treatment differences in RAMRIQ synovitis were statistically significant at month 3, consistent with DCE MRI findings. Less deterioration of RAMRIS and RAMRIQ erosive damage was seen at months 6 and 12 in both tofacitinib groups versus MTX monotherapy.

Conclusions These results provide consistent evidence using three different MRI technologies that tofacitinib treatment leads to early reduction of inflammation and inhibits progression of structural damage.

Trial registration number NCT01164579.

\section{INTRODUCTION}

Inflammation of the synovium, particularly the bone marrow, measured using MRI, has been identified as a prognostic indicator of structural joint damage in patients with rheumatoid arthritis (RA). ${ }^{1-3}$ Inhibition of this damage at an early stage in the disease course is desirable to limit disability ${ }^{4}$ and impact on general health and quality of life. ${ }^{5}$

Tofacitinib is an oral Janus kinase (JAK) inhibitor for the treatment of RA. The efficacy and safety of tofacitinib 5 and $10 \mathrm{mg}$ twice daily in patients with active moderate-to-severe RA has been demonstrated in randomised, double-blind, phase $2^{6-10}$ and phase $3^{11-16}$ studies of up to 24 months duration and in open-label, long-term extension studies with up to 96 months of observation. ${ }^{17}$ The inhibition of structural damage in patients who received tofacitinib has been shown using plain-film radiography. ${ }^{14} 15$

MRI measures provide improved sensitivity versus conventional radiography. ${ }^{18-20}$ Bone marrow oedema (BME) and synovitis, measured using MRI, have been shown to be highly sensitive to treatment with conventional synthetic disease-modifying antirheumatic drugs. ${ }^{21-25}$ However, few randomised clinical trials have been published using MRI outcomes as primary endpoints in patients with early RA. ${ }^{21} 23$ 26-28 The validated, semiquantitative assessment of multiple pathologies using the Outcome Measures in Rheumatology Clinical Trials (OMERACT) RA MRI score (RAMRIS) ${ }^{29}$ has become the standard for MRI trials. ${ }^{20}$ Quantitative MRI measures offer the opportunity to improve on the responsiveness of semiquantitative scoring. Dynamic contrast-enhanced (DCE) MRI measurements show strong correlation with histological assessments of synovitis ${ }^{30}$ and have demonstrated sensitivity in detecting therapy-induced changes in synovitis in patients with early RA. ${ }^{31}$ Preliminary work with active appearance modelling (AAM) ${ }^{33}$ RA MRI quantification (RAMRIQ) of all involved 
joint tissues has suggested improved responsiveness over RAMRIS. $^{34}$

Patients with early RA have participated in previous studies of tofacitinib, although the lowest mean duration of RA was approximately 3 years. ${ }^{14}$ This is the first study to explore the effects of tofacitinib, as monotherapy or in combination with methotrexate (MTX; vs MTX with placebo), on a range of highly sensitive MRI endpoints, exclusively in patients with early RA.

\section{METHODS}

\section{Study design and conduct}

This was an exploratory, phase 2, randomised, double-blind, double-dummy, parallel-group study (A3921068; NCT01164579), conducted at 24 centres in Central and Latin
America, Europe and the USA (25 October 2010-5 November 2013). Study end was the month 12 visit or early termination for patients who discontinued.

\section{Randomisation and treatment}

At baseline, patients were randomised 1:1:1 using an automated web/telephone randomisation system to tofacitinib $10 \mathrm{mg}$ twice daily with MTX, tofacitinib $10 \mathrm{mg}$ twice daily with placebo (tofacitinib monotherapy) or MTX with placebo (MTX monotherapy), for 12 months. Tofacitinib $10 \mathrm{mg}$ twice daily was administered orally as two $5 \mathrm{mg}$ tablets twice daily. MTX was administered orally in capsule form and titrated, if tolerated, from $10 \mathrm{mg}$ once weekly $(4 \times 2.5 \mathrm{mg}$ capsules $)$ to $15 \mathrm{mg}$ once weekly $(6 \times 2.5 \mathrm{mg}$ capsules $)$ at the end of month 1 , and $20 \mathrm{mg}$ once weekly $(8 \times 2.5 \mathrm{mg}$ capsules $)$ at the end of month 2 .

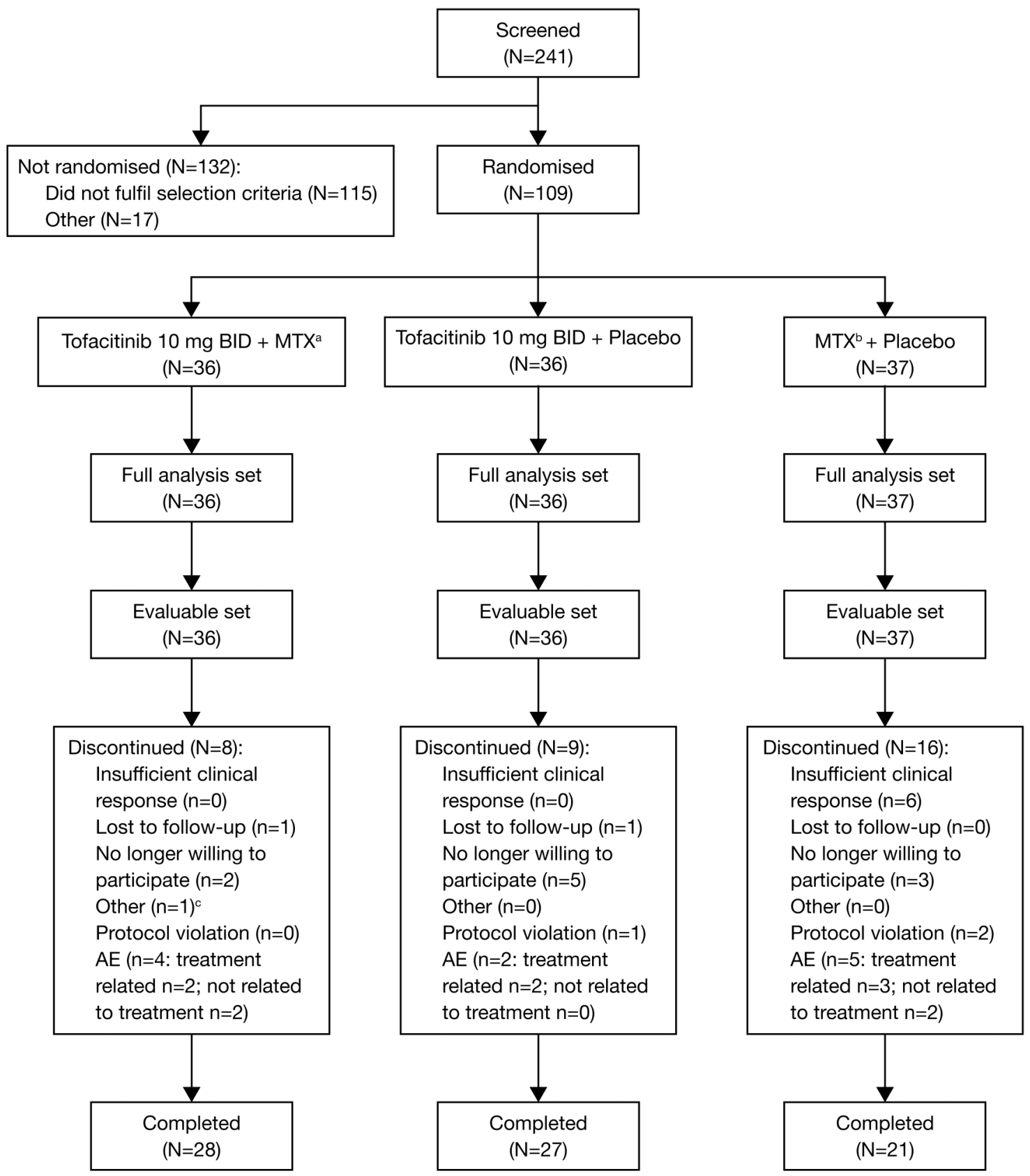

Figure 1 Patient disposition. ${ }^{a}$ Mean dose of methotrexate (MTX) at month 3 was $18.3 \mathrm{mg}$ weekly; ${ }^{b}$ mean dose of MTX at month 3 was 19.0 mg weekly; 'could not attend scheduled visits due to work. $A E$, adverse event; BID, twice daily; $N$, number of patients in population or analysis set; $\mathrm{n}$, number of patients with an event. 
Placebo was matched to tofacitinib or MTX, according to randomisation.

\section{Patients}

Eligible patients were aged $\geq 18$ years; active RA ( $>6$ tender/ painful joints/ $>6$ swollen joints) of $\leq 2$ years duration since diagnosis; erythrocyte sedimentation rate (ESR; Westergren method) $>28 \mathrm{~mm} / \mathrm{h}$, or C-reactive protein $>7 \mathrm{mg} / \mathrm{L}$. Patients were generally MTX-naive, although $<3$ weekly doses of MTX were permitted after a 4-week washout of MTX, unless MTX had been stopped due to a related adverse event (AE). Key eligibility criteria included unequivocal evidence of $\geq 1$ joint erosion on hand/wrist radiographs (assessed at the study centre), plus clinical evidence of synovitis (tenderness/pain or swelling, or both; confirmed by MRI at the study centre); see online supplementary materials for additional details.

Patients were excluded if they had received prior biological disease-modifying antirheumatic drugs therapy; background arthritis therapy is detailed in the supplementary materials. Other exclusion criteria included replacement of an metacarpophalangeal (MCP) or wrist joint within the index wrist or hand, any contraindications to MRI (glomerular filtration rate $<60 \mathrm{~mL} / \mathrm{min}$ ) or previous reaction to gadolinium contrast agent. Patients with malignancies, lymphoproliferative disorder, evidence of untreated latent or active tuberculosis, serious infection $\leq 6$ months previous or infection requiring antimicrobial therapy $\leq 2$ weeks previous were also excluded.

\section{MRI assessments}

MRIs were obtained at screening, and at months 1, 3, 6 and 12, using clinical scanners $(1.5$ or $3.0 \mathrm{~T})$. The same scanner was used serially at any given centre. The contrast agent $(0.1 \mathrm{mmol} / \mathrm{kg}$ gadolinium) was administered intravenously with an infusion pump. Images included coronal short tau inversion recovery images, pre-contrast and post-contrast coronal T1-weighted (T1w) fat-suppressed gradient echo images, axial DCE T1w gradient echo images and post-contrast axial T1w fat-suppressed spin echo images. Example images are shown in the online supplementary materials.

\section{RAMRIS}

MRI BME, synovitis and bone erosions in the index hand (MCP joints 1-5) and wrist were scored according to OMERACT RAMRIS $^{35}$ by one centralised reader blinded to time sequence and treatment. The presence of any MRI-detected synovitis in the studied joints that were evaluated with RAMRIS (wrist and MCP joints 2-5) was used as MRI confirmation of clinical inclusion.

\section{RAMRIQ}

RAMRIQ measurements of BME, synovitis and erosions in the wrist and MCP joints 2-5 were performed by Imorphics (Manchester, UK) using automated methods. RAMRIQ assessed the same pathologies and joints (excepting MCP1) as RAMRIS, allowing for direct comparison of results obtained

Table 1 Summary of patient demographics and baseline characteristics

\begin{tabular}{|c|c|c|c|}
\hline Parameter & $\begin{array}{l}\text { Tofacitinib } 10 \text { mg twice } \\
\text { daily + MTX }(\mathrm{N}=36)\end{array}$ & $\begin{array}{l}\text { Tofacitinib } 10 \mathrm{mg} \text { twice daily } \\
\text { monotherapy }(\mathrm{N}=36)\end{array}$ & $\begin{array}{l}\text { MTX monotherapy } \\
(\mathrm{N}=37)\end{array}$ \\
\hline Age, mean (SD) & $47.8(12.3)$ & $50.8(12.8)$ & $47.8(11.6)$ \\
\hline Females, \% & 86.1 & 83.3 & 78.4 \\
\hline Mean duration of disease, years (range) & $0.8(0.1-2.2)$ & $0.8(0.1-8.5)$ & $0.6(0.1-1.9)$ \\
\hline Positive for rheumatoid factor, $\mathrm{n} / \mathrm{N}(\%)$ & $26 / 34(76.5)$ & $27 / 35(77.1)$ & $27 / 37(73.0)$ \\
\hline Anti-CCP positive, n/N (\%) & $27 / 34(79.4)$ & $27 / 35(77.1)$ & $30 / 37(81.8)$ \\
\hline Swollen joint count, mean (range) & $13.4(0.0-32.0)$ & $15.3(4.0-46.0)$ & $14.4(6.0-39.0)$ \\
\hline Tender joint count, mean (range) & $20.6(0.0-57.0)$ & $20.9(4.0-53.0)$ & $20.5(9.0-52.0)$ \\
\hline DAS28-4(ESR), mean (SD)* & $6.3(0.9)$ & $6.5(0.8)$ & $6.4(0.8)$ \\
\hline HAQ-DI score, mean (SD)* & $1.5(0.8)$ & $1.5(0.6)$ & $1.5(0.7)$ \\
\hline \multicolumn{4}{|l|}{ RAMRIS, mean (SD) $\dagger$} \\
\hline BME & $1.9(3.7)$ & $2.6(3.7)$ & $2.2(5.1)$ \\
\hline Synovitis & $5.8(3.8)$ & $5.7(3.5)$ & $5.3(3.9)$ \\
\hline Bone erosions & $9.4(10.8)$ & $7.5(7.6)$ & $12.2(14.9)$ \\
\hline \multicolumn{4}{|l|}{ RAMRIQ, mean $(S D)^{*}$} \\
\hline BME & $1.4(2.8)$ & $1.1(2.7)$ & $1.4(2.7)$ \\
\hline Synovitis & $7750.4(5432.8)$ & $7971.8(5510.1)$ & $6980.7(6304.8)$ \\
\hline Bone erosions & $1.6(0.9)$ & $1.6(0.8)$ & $1.9(1.3)$ \\
\hline DCE MRI N $\mathrm{V}_{\text {Vox }}$, mean (SD) $\ddagger$ & $3013.6(3605.6)$ & $2767.6(2140.2)$ & $3079.8(3704.9)$ \\
\hline \multicolumn{4}{|l|}{ Radiographic evaluations, mean (SD)† } \\
\hline van der Heijde mTSS & $13.0(21.7)$ & $12.6(26.0)$ & $13.7(26.0)$ \\
\hline JSN component score & $6.9(13.3)$ & $5.7(15.0)$ & $6.1(12.7)$ \\
\hline Erosion component score & $6.1(9.3)$ & $6.9(11.8)$ & $7.6(14.3)$ \\
\hline Prior $\mathrm{MTX}, \mathrm{n}(\%) \S$ & $0(0.0)$ & $2(5.6)$ & $4(10.8)$ \\
\hline Prior/concomitant systemic corticosteroids, n (\%) & $20(55.6)$ & $16(44.4)$ & $21(56.8)$ \\
\hline
\end{tabular}

*Evaluable set: tofacitinib with MTX (N=36), tofacitinib monotherapy $(\mathrm{N}=36)$, MTX monotherapy $(\mathrm{N}=37)$.

†Evaluable set: tofacitinib with MTX $(\mathrm{N}=34)$, tofacitinib monotherapy $(\mathrm{N}=36)$, MTX monotherapy $(\mathrm{N}=37)$.

‡Evaluable set: tofacitinib with MTX $(\mathrm{N}=34)$, tofacitinib monotherapy $(\mathrm{N}=32)$, MTX monotherapy $(\mathrm{N}=32)$.

$\S$ Patients who had received $<3$ weekly doses of MTX were permitted to participate following a 4-week washout of MTX unless MTX had been stopped due to a related adverse event. BME, bone marrow Oedema; CCP, cyclic-citrullinated peptide; DAS28-4(ESR), Disease Activity Score in 28 joints with 4 variables including erythrocyte sedimentation rate; DCE MRI,

dynamic contrast-enhanced MRI; HAQ-DI, Health Assessment Questionnaire-Disability Index; JSN, joint space narrowing; MTX, methotrexate; mTSS, van der Heijde modification of the total Sharp score; $\mathrm{N}_{\mathrm{Vox}}$, number of enhancing voxels; RAMRIQ, quantitative rheumatoid arthritis MRI score; RAMRIS, rheumatoid arthritis MRI score. 
using the two methods. Bones were automatically identified in pre-contrast, coronal T1 images using AAMs. ${ }^{33}$ Joint capsules and soft tissues were also segmented with AAMs, providing consistent 3D regions of interest (ROI) for synovial enhancement across all time points. Oedema volume was defined as non-erosion contrast-enhancing voxels inside the bone. Synovial volume was calculated as voxels that enhance within each ROI. Erosion volume was identified inside the bone surfaces using voxel-based classification. The volume of $\mathrm{BME}$ and erosions was normalised to total bone volume for statistical analysis.

\section{DCE MRI}

DCE MRI was captured for the wrist only. ROIs were defined by a radiologist within the area encompassing the distal radioulnar joint, the radiocarpal joint and the intercarpal-carpometacarpophalangeal joints. The number of enhancing voxels $\left(\mathrm{N}_{\mathrm{Vox}}\right)$, initial rate of enhancement (IRE) and maximum enhancement $\left(\mathrm{E}_{\mathrm{Max}}\right)$,with plateau and washout patterns, were automatically extracted from ROIs and the sum $\left(\mathrm{N}_{\mathrm{Vox}}\right)$ or average (IRE and $E_{\text {Max }}$ ) of values across three user-defined ROIs was determined using the Dynamika software package (Image Analysis, London, $\left.\mathrm{UK}^{37}\right)$.

\section{Endpoints}

The co-primary endpoints were change from baseline in RAMRIS BME at month 6 , and change from baseline in synovitis at month 3 , in wrist and MCP joints.

Changes from baseline in RAMRIS BME (except month 6), synovitis (except month 3 ) and RAMRIS erosions at months 1 , 3, 6 and 12 were assessed as secondary endpoints. Exploratory endpoints included RAMRIQ assessments of BME, synovitis and erosions; DCE MRI assessment of $\mathrm{N}_{\mathrm{Vox}}$, IRE and $\mathrm{E}_{\mathrm{Max}}$; and proportions of patients with/without progression based on RAMRIS BME, synovitis and erosions.

\section{Radiographic and clinical endpoints}

Posteroanterior hand/wrist and anteroposterior foot radiographs at baseline, month 6 and month 12, were assessed as secondary endpoints using the van der Heijde modification of the total Sharp score (mTSS)—range 0-488, with higher scores indicating greater structural joint damage. ${ }^{38}$ Radiographs were scored by a centralised reader blinded to time sequence and treatment received.

Clinical endpoints included American College of Rheumatology (ACR)20, ACR50 and ACR70 responses; proportion of patients achieving a Disease Activity Score (DAS28-4

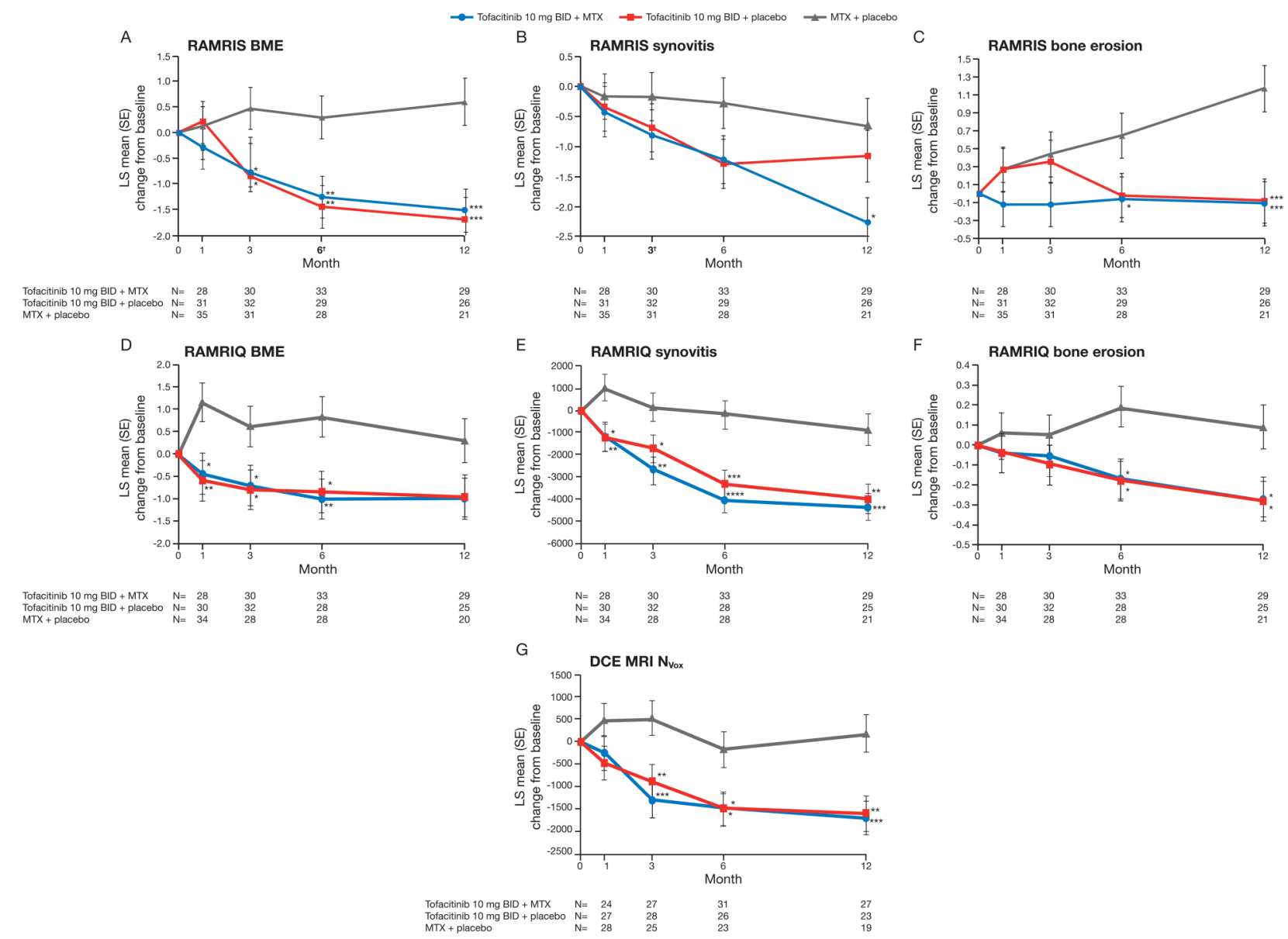

Figure 2 Least squares (LS) mean change from baseline in wrist and metacarpophalangeal (MCP): (A) rheumatoid arthritis MRI score (RAMRIS) bone marrow oedema (BME), (B) RAMRIS synovitis, (C) RAMRIS bone erosions, (D) quantitative rheumatoid arthritis MRI score (RAMRIQ) BME, (E) RAMRIQ synovitis, (F) RAMRIQ bone erosions and wrist (G) dynamic contrast-enhanced MRI (DCE MRI) number of enhancing voxels ( $\mathrm{N}_{\text {Vox }}$ ) (evaluable set). ${ }^{*} p<0.05,{ }^{* *} p<0.01,{ }^{* * *} p<0.001,{ }^{* * * *} p<0.0001$ vs methotrexate (MTX) monotherapy, using a mixed-effect model for repeated measures. MRI measurements were based on one hand (most symptomatic at baseline). RAMRIS and RAMRIQ scores relate to MRIs of the index hand (MCP joints $1-5$ and $2-5$, respectively) and wrist. DCE MRI measurements relate to MRIs of the index wrist using regions of interest (ROIs) defined within the area encompassing the distal radioulnar joint, the radiocarpal joint and the intercarpal-carpometacarpophalangeal joints. BID, twice daily. 
[ESR]) $<2.6$ (remission) or $\leq 3.2$ (low disease activity); and improvement from baseline in Health Assessment Questionnaire-Disability Index (HAQ-DI) score $\geq 0.22$.

\section{Safety assessments}

AEs and clinical laboratory abnormalities were recorded. Medical Dictionary for Regulatory Activities V.16.1 was used.

\section{Statistical analyses}

This was an exploratory study. Sample size was determined by change from baseline in RAMRIS BME score at month 6 and RAMRIS synovitis score at month 3 . A sample size of 30 patients per arm provided $>80 \%$ probability to show a statistical difference between arms at the two-sided $\alpha$ of 0.1 . Owing to an observed dropout rate of $\sim 20 \%$, approximately 110 patients were to be enrolled to obtain 90 evaluable patients for the primary endpoint analysis. Given the exploratory nature of the study, statistical significance was assessed at the 10\% (two-sided) level. For reporting purposes, treatment differences with $\mathrm{p}<0.05$ (vs MTX monotherapy) were considered significant.

The evaluable set-all patients who were randomised to study treatment, received $\geq 1$ dose of randomised investigational drug and had available data at baseline and the indicated time point -was used for the efficacy analyses.
Primary and secondary continuous efficacy endpoints were assessed using a mixed-effect model for repeated measures, with treatment arms as factors and baseline as a covariate. Categorical endpoints were summarised by frequency (n, \%). For efficacy endpoints, 90\% CIs were included for the difference in proportions between the treatment arms. Procedures for handling missing MRI values are provided in the online supplementary materials.

Cumulative probability plots examined the distribution of changes from baseline in OMERACT RAMRIS measures and van der Heijde mTSS. The smallest detectable changes (SDCs) for RAMRIS BME, synovitis and bone erosion measurements were determined according to the method described by Bruynesteyn et al ${ }^{39}$ using month 6 MRI data from 10 patients; read twice by the same reader with $>4$ weeks between readings to minimise any recall bias. SDCs for RAMRIS BME, synovitis and erosion scores were $1.85,2.77$ and 0.85 , respectively.

\section{RESULTS}

\section{Patient disposition and demographics}

Of 109 patients randomised, 36 received tofacitinib with MTX, 36 received tofacitinib monotherapy and 37 received MTX monotherapy (figure 1). Baseline demographics and disease characteristics were generally well balanced between groups (table 1). Fewer patients who received MTX monotherapy

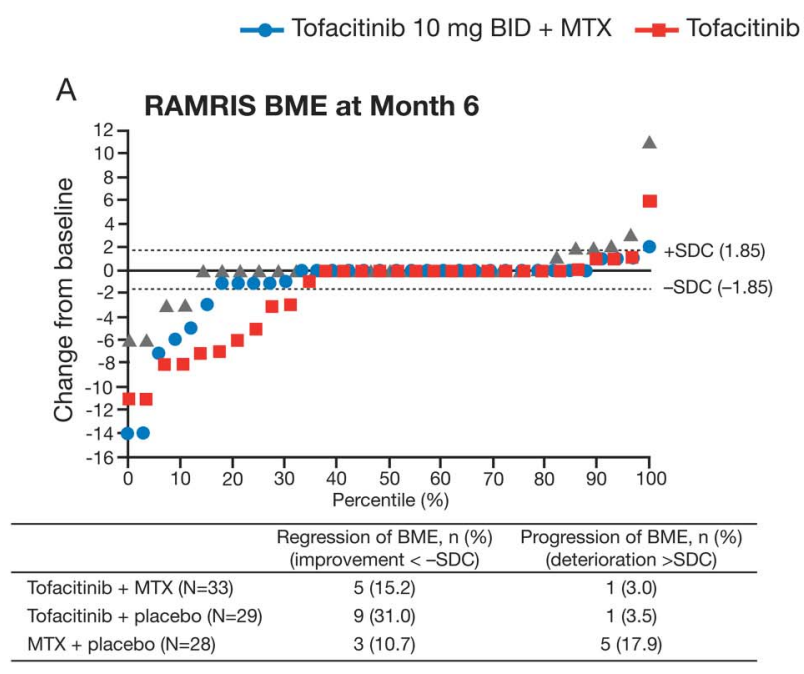

$10 \mathrm{mg}$ BID + placebo $\longleftarrow$ MTX + placebo
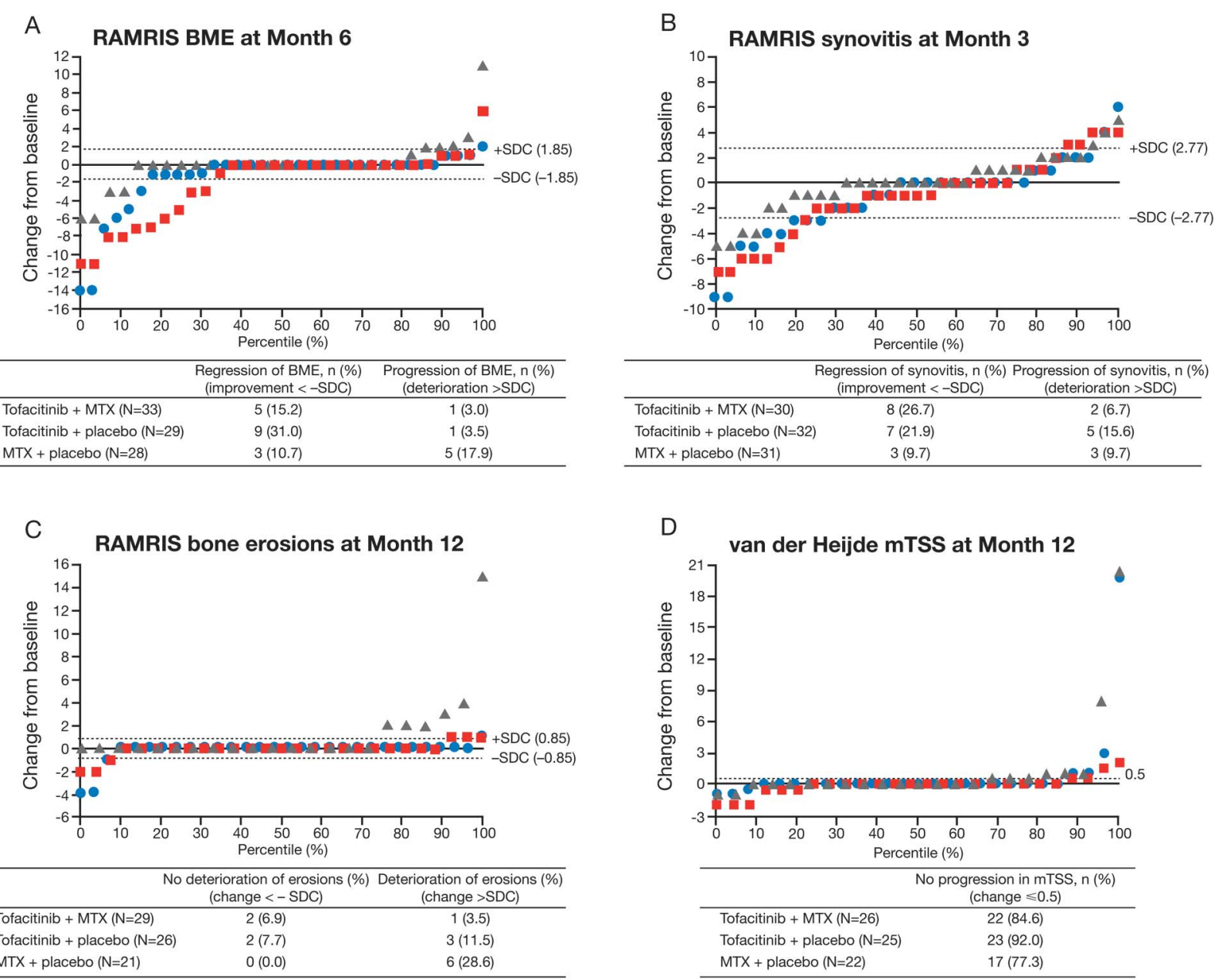

Figure 3 Cumulative probability plots for rheumatoid arthritis MRI score (RAMRIS) endpoints and van der Heijde modification of the total Sharp score (mTSS). The distribution of changes by percentile is shown. BID, twice daily; BME, bone marrow oedema; MCP, metacarpophalangeal; MTX, methotrexate; SDC, smallest detectable change. 
completed the study $(58.3 \%(\mathrm{n}=21))$ versus those who received tofacitinib with MTX $(77.8 \%(n=28))$ or tofacitinib monotherapy $(75.0 \%(\mathrm{n}=27))$.

\section{Co-primary endpoints}

Treatment differences (90\% CI) in RAMRIS BME at month 6 were $-1.55(-2.52$ to -0.58$)$ for tofacitinib with MTX and $-1.74(-2.72$ to -0.76$)$ for tofacitinib monotherapy (both $\mathrm{p}<0.01$ vs MTX monotherapy; figure 2A). Corresponding changes from baseline in RAMRIS synovitis score at month 3 were $-0.63(-1.58$ to $0.31 ; \mathrm{p}=0.27)$ and $-0.52(-1.46$ to $0.41 ; \mathrm{p}=0.36$ ) (figure $2 \mathrm{~B}$ ).

\section{Secondary and exploratory endpoints RAMRIS}

The treatment difference $(90 \% \mathrm{CI})$ in RAMRIS BME at month 3 was $-1.24(-2.21$ to -0.27$)$ for tofacitinib with MTX and $-1.32(-2.28$ to -0.37$)$ for tofacitinib monotherapy (both $\mathrm{p}<0.05$ vs MTX monotherapy). Significant differences were maintained to month 12 (figure 2A). Improvements from baseline in RAMRIS synovitis were observed in all groups up to month 12 . While improvements were numerically greater in both tofacitinib groups versus MTX monotherapy at all time points assessed, differences were not generally significant (figure 2B). Less deterioration in RAMRIS erosion scores was noted from month 1 onwards in patients receiving tofacitinib with MTX, versus MTX monotherapy (figure 2C). Treatment differences $(90 \% \mathrm{CI})$ in RAMRIS erosions at month 6 were $-0.71(-1.29$ to $-0.12)$ for tofacitinib with MTX ( $p<0.05$ vs MTX) and -0.67 $(-1.25$ to -0.08$)$ for tofacitinib monotherapy $(\mathrm{p}=0.06$ vs MTX). Corresponding changes at month 12 were $-1.29(-1.90$ to -0.69$)$ and $-1.26(-1.87$ to -0.65 ; both $\mathrm{p}<0.001)$. Mean values for all RAMRIS measures over time are presented in online supplementary table S1.

\section{Post hoc cumulative probability plots for RAMRIS endpoints}

In general, more patients receiving tofacitinib showed regression (ie, improvement <-SDC) in RAMRIS BME (month 6) and synovitis (month 3) versus MTX monotherapy, and a smaller proportion demonstrated progression (ie, deterioration $>$ SDC) (figure 3A,B). The MTX monotherapy group contained a greater proportion of patients with deterioration of erosive damage at month 12 versus both tofacitinib groups (figure 3C). This was mirrored by a smaller proportion of patients with no progression in van der Heijde mTSS (change $\leq 0.5$ ) at month 12 in the MTX monotherapy group versus either tofacitinib groups (figure $3 \mathrm{D}$ ).

\section{RAMRIQ and DCE MRI}

Reductions from baseline in RAMRIQ BME and synovitis were observed for both tofacitinib groups from month 1 to month 12 (figure 2D,E). Treatment differences were significant $(\mathrm{p}<0.05$ vs MTX monotherapy) through month 6 for BME and through month 12 for synovitis (figure 2D,E). Treatment differences in RAMRIQ bone erosion scores showed significantly less deterioration of erosive damage at months 6 and 12 in both tofacitinib groups versus MTX monotherapy (all $\mathrm{p}<0.05$ ) (figure $2 \mathrm{~F}$ ).

DCE MRI measurements $\left(\mathrm{N}_{\mathrm{Vox}}\right)$ indicated significant improvements from baseline in synovitis at month 3 for both tofacitinib groups ( $p<0.01$ vs MTX monotherapy) (figure $2 \mathrm{G}$ ). Improvements remained significant $(\mathrm{p}<0.05)$ through month 12 (figure 2G). Mean values for RAMRIQ and DCE MRI measures over time can be found in online supplementary table S1. Least squares (LS) mean changes from baseline in IRE and $\mathrm{E}_{\mathrm{Max}}$ are shown in online supplementary figure S1.
Radiographic assessments

Numerical changes from baseline in van der Heijde mTSS, joint space narrowing and erosion component scores were small in all treatment arms at months 6 and 12 (table 2).

\section{Clinical response}

Numerically higher ACR20, ACR50 and ACR70 response rates were observed at months 3,6 and 12 in the tofacitinib groups versus MTX monotherapy (table 2). The proportion of patients

Table 2 Radiographic and clinical endpoints (evaluable set, LOCF)

$\begin{array}{lll}\text { Tofacitinib } & \text { Tofacitinib } 10 \mathrm{mg} & \\ 10 \mathrm{mg} \text { twice } & \text { twice daily } & \text { MTX } \\ \text { daily + MTX } & \text { monotherapy } & \text { monotherapy }\end{array}$

LS mean change from baseline (SE)

van der Heijde mTSS

\begin{tabular}{|c|c|c|c|}
\hline Month $6 \dagger$ & $0.44(0.50)$ & $-0.14(0.51)$ & $0.93(0.52)$ \\
\hline Month 12 & $0.85(0.51)$ & $-0.15(0.52)^{*}$ & $1.36(0.54)$ \\
\hline \multicolumn{4}{|l|}{ JSN component score } \\
\hline Month $6 \dagger$ & $0.29(0.34)$ & $-0.06(0.35)$ & $0.35(0.36)$ \\
\hline Month $12 \ddagger$ & $0.43(0.35)$ & $-0.12(0.36)$ & $0.71(0.37)$ \\
\hline \multicolumn{4}{|c|}{ Erosion component score } \\
\hline Month $6 \dagger$ & $0.16(0.24)$ & $-0.10(0.25)$ & $0.58(0.25)$ \\
\hline Month 12‡ & $0.42(0.25)$ & $-0.05(0.26)$ & $0.65(0.27)$ \\
\hline \multicolumn{4}{|l|}{ Responders, \% (SE) } \\
\hline ACR20 & $\mathrm{N}=35$ & $\mathrm{~N}=36$ & $\mathrm{~N}=37$ \\
\hline Month 3 & $77.1(7.1)$ & $66.7(7.9)$ & $56.8(8.1)$ \\
\hline Month 6 & $77.1(7.1)^{*}$ & $72.2(7.5)$ & $54.1(8.2)$ \\
\hline Month 12 & $82.9(6.4)$ & $66.7(7.9)$ & $56.8(8.1)$ \\
\hline ACR50 & $\mathrm{N}=35$ & $\mathrm{~N}=36$ & $\mathrm{~N}=37$ \\
\hline Month 3 & $48.6(8.4)$ & $55.6(8.3)^{*}$ & $29.7(7.5)$ \\
\hline Month 6 & $57.1(8.4)^{* *}$ & $52.8(8.3)^{*}$ & $27.0(7.3)$ \\
\hline Month 12 & $65.7(8.0)^{* *}$ & $50.0(8.3)$ & $35.1(7.8)$ \\
\hline ACR70 & $\mathrm{N}=35$ & $\mathrm{~N}=36$ & $\mathrm{~N}=37$ \\
\hline Month 3 & $25.7(7.4)$ & $27.8(7.5)$ & $13.5(5.6)$ \\
\hline Month 6 & $34.3(8.0)$ & $30.6(7.7)$ & $24.3(7.1)$ \\
\hline Month 12 & $28.6(7.6)$ & $33.3(7.9)$ & $24.3(7.1)$ \\
\hline DAS28-4(ESR) $<2.6$ & $\mathrm{~N}=34$ & $\mathrm{~N}=36$ & $\mathrm{~N}=37$ \\
\hline Month 3 & $23.5(7.3)$ & $2.8(2.7)$ & $13.5(5.6)$ \\
\hline Month 6 & $29.4(7.8)$ & $13.9(5.8)$ & $13.5(5.6)$ \\
\hline Month 12 & $35.3(8.2)^{*}$ & $19.4(6.6)$ & $13.5(5.6)$ \\
\hline DAS28-4(ESR) $\leq 3.2$ & $\mathrm{~N}=34$ & $\mathrm{~N}=36$ & $\mathrm{~N}=37$ \\
\hline Month 3 & $32.4(8.0)$ & $30.6(7.7)$ & $16.2(6.1)$ \\
\hline Month 6 & $41.2(8.4)$ & $27.8(7.5)$ & $21.6(6.8)$ \\
\hline Month 12 & $58.8(8.4)^{\star * *}$ & $30.6(7.7)$ & $18.9(6.4)$ \\
\hline $\begin{array}{l}\text { HAQ-DI improvement } \\
\geq 0.22 \S\end{array}$ & $\mathrm{N}=34$ & $\mathrm{~N}=36$ & $\mathrm{~N}=37$ \\
\hline Month 3 & $73.5(7.6)$ & $75.0(7.2)$ & $81.1(6.4)$ \\
\hline Month 6 & $76.5(7.3)$ & $75.0(7.2)$ & $70.3(7.5)$ \\
\hline Month 12 & $73.5(7.6)$ & $72.2(7.5)$ & $73.0(7.3)$ \\
\hline
\end{tabular}

${ }^{*} p<0.05,{ }^{* *} p<0.01,{ }^{* *} p<0.001$ vs MTX monotherapy.

tThe numbers of patients evaluable at Month 6 were 29,27 and 28 in the tofacitinib with MTX, tofacitinib monotherapy and MTX monotherapy groups, respectively. $¥$ The numbers of patients evaluable at Month 12 were 26,25 and 22 in the tofacitinib with MTX, tofacitinib monotherapy and MTX monotherapy groups, respectively. §Improvement vs baseline.

ACR, American College of Rheumatology response criteria; DAS28-4(ESR), Disease Activity Score in 28 joints with 4 variables including erythrocyte sedimentation rate; HAQ-DI, Health Assessment Questionnaire-Disability Index; JSN, joint space narrowing; LOCF, last observation carried forward; LS, least squares; mTSS, van der Heijde modification of the total Sharp score; MTX, methotrexate; N, number of patients with values at baseline and time point of interest. 
who achieved DAS28-4(ESR) $<2.6$ increased over time in both tofacitinib groups, whereas corresponding values in the MTX monotherapy group remained low and stable (table 2). More patients receiving tofacitinib (vs MTX monotherapy) achieved DAS28-4(ESR) $\leq 3.2$ from month 3 onwards (table 2). Compared with MTX monotherapy, the proportion of patients achieving an improvement in HAQ-DI $\geq 0.22$ from baseline in the tofacitinib groups was numerically higher at month 6 and similar at month 12 (table 2).
Safety and tolerability

AEs were reported in $78.9 \%$ of patients (86/109), of which $96.1 \%(245 / 255)$ were mild or moderate. AEs are summarised in table 3. Five patients had serious AEs, one of which (anal abscess in a patient receiving tofacitinib with MTX) was considered treatment-related by the investigator, resulted in permanent discontinuation, and was the only serious infection reported. No deaths were reported. Eleven patients discontinued due to AEs (any cause). Liver function test

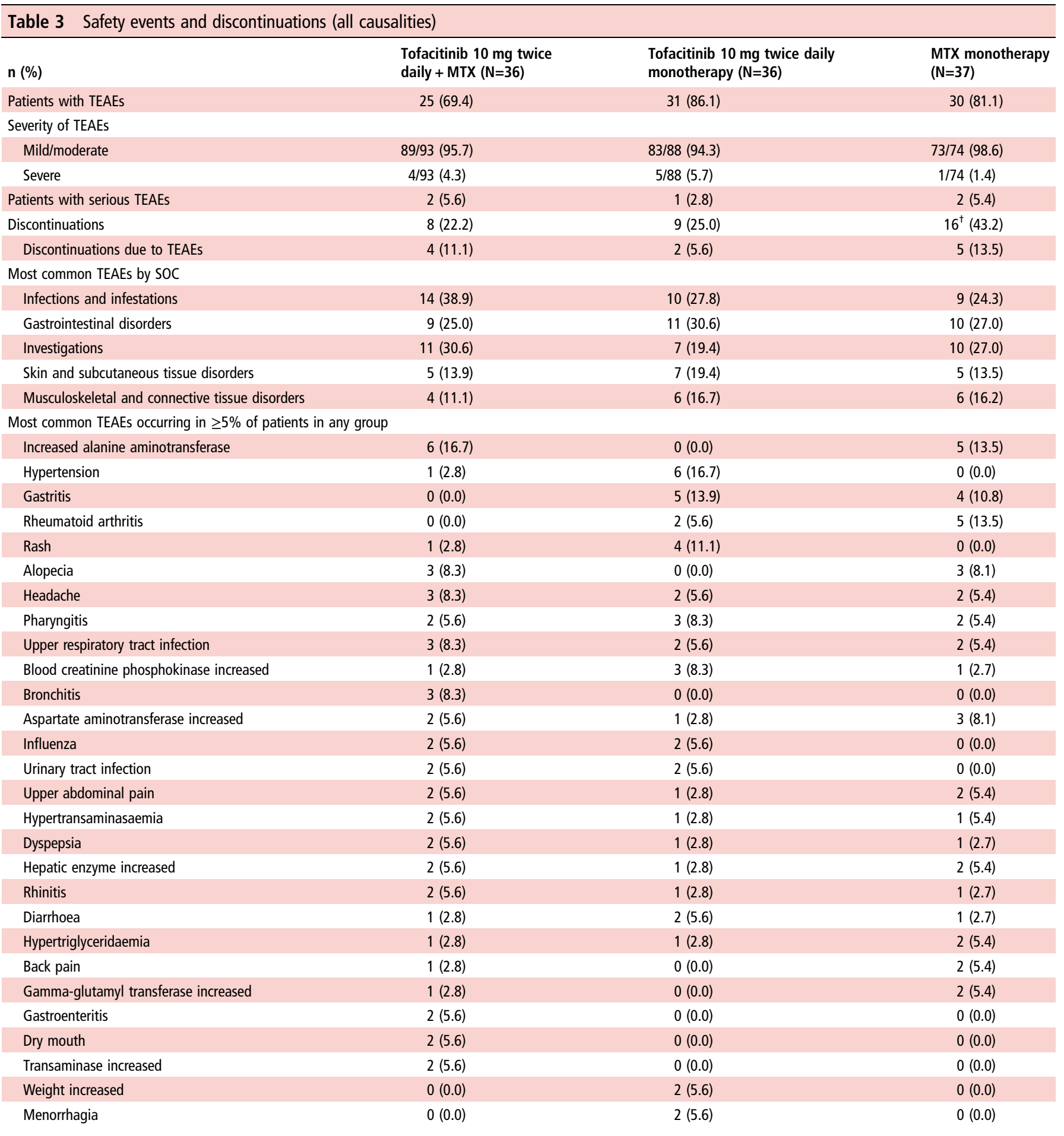

tDiscontinuations due to: insufficient clinical response $(n=6) ; A E(n=5$; of which 3 were related to study drug); patient no longer willing to participate in study ( $n=3)$; and protocol violation $(\mathrm{n}=2)$.

MTX, methotrexate; N, number of patients treated; $n$, number of unique patients with events; SOC, system organ class; TEAEs, treatment-emergent adverse events. 
abnormalities were the most common $\mathrm{AE}$ that resulted in discontinuation: two patients receiving tofacitinib with MTX, and four patients receiving MTX monotherapy. Six patients receiving MTX monotherapy discontinued due to insufficient clinical response-no tofacitinib-treated patients discontinued for this reason.

There were few differences between treatment groups: nine patients $(8.3 \%)$ had severe AEs, of which eight $(7.3 \%)$ were randomised to tofacitinib ( $\mathrm{n}=4$ in each tofacitinib group); and the proportion of patients with infections (any cause) was higher for tofacitinib with MTX versus the monotherapy groups (table 3).

\section{DISCUSSION}

This novel imaging study in patients with early RA provides evidence that tofacitinib $10 \mathrm{mg}$ twice daily, administered as monotherapy or in combination with MTX, can improve MRI outcomes related to tissue inflammation that have been identified as prognostic indicators for joint damage. ${ }^{1}{ }^{40}$ All MRI methodologies demonstrated reduced inflammation in the synovium and bone marrow with tofacitinib. Numerical trends in semiquantitative and quantitative MRI data were consistent between the two tofacitinib arms. Furthermore, quantitative methodologies identified significant changes in MRI pathologies (inflammation and erosive damage) as early as month 1 or 3 , and demonstrated suboptimal treatment-related suppression of inflammation and progressive bone erosions with MTX monotherapy. The study met the first of its co-primary endpoints, with highly significant improvements in RAMRIS BME at month 6 observed for both tofacitinib groups versus MTX monotherapy. Statistically significant improvement in RAMRIS synovitis at month 3 versus MTX monotherapy was not met. However, numerical improvements in RAMRIS synovitis were observed in both tofacitinib groups (vs MTX). Furthermore, significant improvements in synovitis scores were observed over time with tofacitinib when quantitative methodologies were used.

The concordance between results obtained using three different MRI techniques underlines the effectiveness of MRI in the evaluation of joint inflammation and damage. All measures were analysed blind to time order, adding to the robustness of the evaluation. The improved differentiation of tofacitinib groups from MTX monotherapy enabled by the quantitative MRI techniques (compared with the semiquantitative RAMRIS method) further validates their use as improved tools for outcome assessment. RAMRIQ is still in development, and increased responsiveness for bone pathologies is expected.

In this study, changes from baseline in van der Heijde mTSS were small in both tofacitinib groups. This finding, together with the relative proportions of patients with progression in mTSS at month 12 in tofacitinib groups (vs MTX monotherapy), is supportive of the lack of radiographic progression noted in previous studies of tofacitinib as monotherapy, or in combination with MTX, in patients with moderate-to-severe RA. ${ }^{14}{ }^{15}$ In the present study, trends in radiographic parameters at months 6 and 12 were consistent with MRI data.

The safety and efficacy of tofacitinib was consistent with phase 3 studies of tofacitinib. ${ }^{11-16}$ No new safety signals were identified in this study.

This was an exploratory study. The RAMRIS SDCs were calculated from intraobserver readings, and this may result in more favourable SDCs than those calculated from interobserver readings. Additionally, the relatively small sample size $(<40$ patients per group) may have introduced certain limitations. Furthermore, approximately half of the patients randomised to MTX monotherapy failed to complete the study. It is possible that had patients not been lost who were failing on MTX monotherapy, larger treatment differences would have been observed for tofacitinib groups versus MTX monotherapy. However, a separate analysis using last observation carried forward for missing values produced findings that were consistent with those of the evaluable set (not shown).

\section{CONCLUSIONS}

These results, obtained using a range of highly sensitive MRI endpoints, and incorporating the validated RAMRIS technique and novel quantitative techniques, provide consistent evidence for the benefits of tofacitinib in reducing inflammation in the synovium and bone marrow, and inhibiting progression of structural damage in patients with early RA. The novel, quantitative methods used here may, after further validation, prove more sensitive and discriminating than conventional semiquantitative scoring.

\section{Author affiliations}

${ }^{1}$ Leeds Institute of Rheumatic and Musculoskeletal Medicine, University of Leeds and NIHR Leeds Musculoskeletal Biomedical Research Unit, Chapel Allerton Hospital, Leeds, UK

${ }^{2}$ Copenhagen Center for Arthritis Research, Center for Rheumatology and Spine Diseases, Rigshospitalet, Glostrup, and Department of Clinical Medicine, University of Copenhagen, Copenhagen, Denmark

${ }^{3}$ Imorphics Ltd, Manchester, UK

${ }^{4}$ Bioclinica Inc., Newark, California, USA

${ }^{5}$ Department of Rheumatology, Leiden University Medical Center, Leiden, The Netherlands

${ }^{6}$ Centro de Investigación y Tratamiento Reumatológico SC.CINTRE, México City, México

${ }^{7}$ Mindful Rheumatix, San Juan, Puerto Rico

${ }^{8}$ Department of Rheumatology and Clinical Immunology, Poznan University of Medical Sciences, Poznan, Poland

${ }^{9}$ Pfizer Inc, Groton, Connecticut, USA

Acknowledgements The authors would like to thank the study A3921068 investigators, staff and patients.

Contributors The study was planned and designed by PGC, MØ, JDB, ZX, RZ, BTW, KS and BW. Statistical analyses were planned and executed by RZ. Study data were collected by FI-P, OS-R and PH. Specialist input on interpretation of study data was provided by PGC and MØ (all MRI measures), CW and TF (RAMRIS), MAB (RAMRIQ and DCE MRI) and DvdH (radiography). All authors were involved with drafting and critical evaluation of the manuscript, and approved the final version for submission. All authors meet the criteria for authorship as stipulated in the guidelines of the Uniform Requirements for Manuscripts submitted to Biomedical Journals.

Funding The study was sponsored by Pfizer Inc. Data analysis support was provided by Shirsendu Sarkar and Swati Rizhwani of Sciformix, and was contracted by Pfizer Inc. Medical writing support was provided by Erin Bekes, PhD, and Claire Cridland of Complete Medical Communications, and was funded by Pfizer Inc. Image analysis support for RAMRIQ was provided by Gwenael Guillard PhD of Imorphics Ltd.

Competing interests PGC is on the speaker's bureau of and has acted as a consultant for, AbbVie, Merck, Novartis, Pfizer Inc, Roche and UCB. MØ has received research grants from Abbott/AbbVie, Centocor, Merck and Schering-Plough, and has acted as a consultant for Abbott/AbbVie, Bristol-Myers Squibb,

Boehringer-Ingelheim, Eli-Lilly, Centocor, GSK, Hospira, Janssen, Merck, Mundipharma, Novartis, Novo, Orion, Pfizer Inc, Regeneron, Sanofi,

Schering-Plough, Roche, Takeda, UCB and Wyeth. MAB is an employee and shareholder of Imorphics Ltd and acted as a paid consultant to Pfizer Inc in connection with analysis of study data. CW and TF are employees of Bioclinica Inc (formerly SYNARC) and acted as paid consultants to Pfizer Inc in connection with analysis of study data. DvdH is a consultant for AbbVie, Amgen, AstraZeneca, Augurex, Bristol-Myers Squibb, Boehringer Ingelheim, Celgene, Centocor, Chugai, Covagen, Daiichi, Eli Lilly, Galapagos, GlaxoSmithKline, Janssen Biologics, Merck, Novartis, Novo-Nordisk, Otsuka, Pfizer Inc, Roche, Sanofi-Aventis, UCB and Vertex 
and is the Director of Imaging Rheumatology BV (not involved in this study). FI-P has received honoraria from Bristol-Myers Squibb, Pfizer Inc, UCB, Janssen and Roche. OS-R has received research grants from AbbVie, Eli Lilly and Pfizer Inc, is on the speaker's bureau of Bristol-Myers Squibb, Genentech, Pfizer Inc and UCB, and is a consultant for Eli Lilly and Genentech. PH has received research grants from, and is a consultant for, Pfizer Inc. At the time of the reported analysis, ZX, RZ, BTW, JDB, KS and BW were all employees and stockholders of Pfizer Inc. BTW is now affiliated to ImaginAb, Inc, Inglewood, California, USA.

Patient consent Obtained.

Ethics approval The study was conducted in compliance with the Declaration of Helsinki, International Conference on Harmonisation Guidelines for Good Clinical Practice and local country regulations. The study protocol and informed consent documentation were approved by the institutional review board or Independent Ethics Committee at each investigational centre.

Provenance and peer review Not commissioned; externally peer reviewed.

Open Access This is an Open Access article distributed in accordance with the Creative Commons Attribution Non Commercial (CC BY-NC 4.0) license, which permits others to distribute, remix, adapt, build upon this work non-commercially, and license their derivative works on different terms, provided the original work is properly cited and the use is non-commercial. See: http://creativecommons.org/ licenses/by-nc/4.0/

\section{REFERENCES}

1 Baker JF, Ostergaard M, Emery P, et al. Early MRI measures independently predict 1-year and 2-year radiographic progression in rheumatoid arthritis: secondary analysis from a large clinical trial. Ann Rheum Dis 2014;73:1968-74.

2 Hetland ML, Ejbjerg B, Hørslev-Petersen K, et al. MRI bone oedema is the strongest predictor of subsequent radiographic progression in early rheumatoid arthritis. Results from a 2-year randomised controlled trial (CIMESTRA). Ann Rheum Dis 2009;68:384-90

3 Haavardsholm EA, Bøyesen $\mathrm{P}$, Østergaard $\mathrm{M}$, et al. Magnetic resonance imaging findings in 84 patients with early rheumatoid arthritis: bone marrow oedema predicts erosive progression. Ann Rheum Dis 2008;67:794-800.

4 Bombardier C, Barbieri M, Parthan A, et al. The relationship between joint damage and functional disability in rheumatoid arthritis: a systematic review. Ann Rheum Dis 2012;71:836-44.

5 Strand V, Singh JA. Improved health-related quality of life with effective disease-modifying antirheumatic drugs: evidence from randomized controlled trials. Am J Manag Care 2007;13(Suppl 9):S237-51.

6 Fleischmann R, Cutolo M, Genovese MC, et al. Phase Illb dose-ranging study of the oral JAK inhibitor tofacitinib (CP-690,550) or adalimumab monotherapy versus placebo in patients with active rheumatoid arthritis with an inadequate response to disease-modifying antirheumatic drugs. Arthritis Rheum 2012;64: $617-29$

7 Kremer JM, Bloom BJ, Breedveld FC, et al. The safety and efficacy of a JAK inhibitor in patients with active rheumatoid arthritis: Results of a double-blind, placebo-controlled phase lla trial of three dosage levels of $\mathrm{CP}-690,550$ versus placebo. Arthritis Rheum 2009:60:1895-905.

8 Kremer JM, Cohen $\mathrm{S}$, Wilkinson BE, et al. A phase Illb dose-ranging study of the oral JAK inhibitor tofacitinib (CP-690,550) versus placebo in combination with background methotrexate in patients with active rheumatoid arthritis and an inadequate response to methotrexate alone. Arthritis Rheum 2012;64: 970-81.

9 Tanaka Y, Suzuki M, Nakamura H, et al. Phase II study of tofacitinib (CP-690,550) combined with methotrexate in patients with rheumatoid arthritis and an inadequate response to methotrexate. Arthritis Care Res (Hoboken) 2011:63:1150-8.

10 Tanaka Y, Takeuchi T, Yamanaka H, et al. Efficacy and safety of tofacitinib as monotherapy in Japanese patients with active rheumatoid arthritis: a 12-week, randomized, Phase 2 study. Mod Rheumatol 2015;25:514-21.

11 Burmester GR, Blanco R, Charles-Schoeman C, et al. Tofacitinib (CP-690,550) in combination with methotrexate in patients with active rheumatoid arthritis with an inadequate response to tumour necrosis factor inhibitors: a randomised phase 3 trial. Lancet 2013:381:451-60.

12 Fleischmann R, Kremer J, Cush J, et al. Placebo-controlled trial of tofacitinib monotherapy in rheumatoid arthritis. N Engl J Med 2012:367:495-507.

13 Kremer J, Li ZG, Hall S, et al. Tofacitinib in combination with nonbiologic disease-modifying antirheumatic drugs in patients with active rheumatoid arthritis: a randomized trial. Ann Intern Med 2013;159:253-61.

14 Lee EB, Fleischmann $R$, Hall $S$, et al. Tofacitinib versus methotrexate in rheumatoid arthritis. N Engl J Med 2014;370:2377-86.

15 van der Heijde D, Tanaka Y, Fleischmann R, et al. Tofacitinib $(C P-690,550)$ in patients with rheumatoid arthritis receiving methotrexate: twelve-month data from a twenty-four-month phase III randomized radiographic study. Arthritis Rheum 2013:65:559-70.

16 van Vollenhoven RF, Fleischmann $\mathrm{R}$, Cohen $\mathrm{S}$, et al. Tofacitinib or adalimumab versus placebo in rheumatoid arthritis. N Engl J Med 2012;367:508-19.

17 Wollenhaupt J, Silverfield J, Lee EB, et al. Tofacitinib, an Oral Janus Kinase Inhibitor, in the Treatment of Rheumatoid Arthritis: Safety and Clinical and Radiographic Efficacy in Open-Label, Long-Term Extension Studies over 7 Years [abstract]. Arthritis Rheum 2015;67(Suppl 10).

18 Peterfy C, Østergaard M, Conaghan PG. MRI comes of age in RA clinical trials. Ann Rheum Dis 2013;72:794-6.

19 Ejbjerg BJ, Vestergaard A, Jacobsen $\mathrm{S}$, et al. The smallest detectable difference and sensitivity to change of magnetic resonance imaging and radiographic scoring of structural joint damage in rheumatoid arthritis finger, wrist, and toe joints: a comparison of the OMERACT rheumatoid arthritis magnetic resonance imaging score applied to different joint combinations and the Sharp/van der Heijde radiographic score. Arthritis Rheum 2005;52:2300-6.

20 American College of Rheumatology Rheumatoid Arthritis Clinical Trials Task Force Imaging Group and Outcome Measures in Rheumatology Magnetic Resonance Imaging Inflammatory Arthritis Working Group. Review: the utility of magnetic resonance imaging for assessing structural damage in randomized controlled trials in rheumatoid arthritis. Arthritis Rheum 2013;65:2513-23.

21 Axelsen MB, Eshed I, Hørslev-Petersen K, et al. A treat-to-target strategy with methotrexate and intra-articular triamcinolone with or without adalimumab effectively reduces MRI synovitis, osteitis and tenosynovitis and halts structural damage progression in early rheumatoid arthritis: results from the OPERA randomised controlled trial. Ann Rheum Dis2015;74:867-75.

22 Conaghan PG, Peterfy $C$, Olech $E$, et al. The effects of tocilizumab on osteitis, synovitis and erosion progression in rheumatoid arthritis: results from the ACT-RAY MRI substudy. Ann Rheum Dis 2014;73:810-16.

23 Durez P, Malghem J, Nzeusseu Toukap A, et al. Treatment of early rheumatoid arthritis: a randomized magnetic resonance imaging study comparing the effects of methotrexate alone, methotrexate in combination with infliximab, and methotrexate in combination with intravenous pulse methylprednisolone. Arthritis Rheum 2007:56:3919-27

24 Haavardsholm EA, Østergaard M, Hammer HB, et al. Monitoring anti-TNFalpha treatment in rheumatoid arthritis: responsiveness of magnetic resonance imaging and ultrasonography of the dominant wrist joint compared with conventional measures of disease activity and structural damage. Ann Rheum Dis 2009:68:1572-9.

25 Kosta PE, Voulgari PV, Zikou AK, et al. Effect of very early treatment in rheumatoid arthritis on bone oedema and synovitis, using magnetic resonance imaging. Scand J Rheumatol 2012:41:339-44.

26 Peterfy C, Durez $\mathrm{P}$, Haraoui $\mathrm{B}$, et al. Response of early rheumatoid arthritis (RA) to treatment with adalimumab plus methotrexate vs. methotrexate alone: magnetic resonance imaging results from OPTIMA [abstract]. Ann Rheum Dis 2010;69(Suppl 3): 455.

27 Conaghan $\mathrm{PG}, \mathrm{O}^{\prime}$ Connor $\mathrm{P}, \mathrm{McG}$ onagle $\mathrm{D}$, et al. Elucidation of the relationship between synovitis and bone damage: a randomized magnetic resonance imaging study of individual joints in patients with early rheumatoid arthritis. Arthritis Rheum 2003:48:64-71.

28 Quinn MA, Conaghan PG, O'Connor PJ, et al. Very early treatment with infliximab in addition to methotrexate in early, poor-prognosis rheumatoid arthritis reduces magnetic resonance imaging evidence of synovitis and damage, with sustained benefit after infliximab withdrawal: results from a twelve-month randomized, double-blind, placebo-controlled trial. Arthritis Rheum 2005:52: $27-35$

29 Døhn UM, Ejbjerg BJ, Hasselquist M, et al. Rheumatoid arthritis bone erosion volumes on CT and MRI: reliability and correlations with erosion scores on CT, MRI and radiography. Ann Rheum Dis 2007;66:1388-92.

30 Axelsen MB, Stoltenberg M, Poggenborg RP, et al. Dynamic gadolinium-enhanced magnetic resonance imaging allows accurate assessment of the synovial inflammatory activity in rheumatoid arthritis knee joints: a comparison with synovial histology. Scand I Rheumatol 2012;41:89-94.

31 Axelsen MB, Ejbjerg BJ, Hetland ML, et al. Differentiation between early rheumatoid arthritis patients and healthy persons by conventional and dynamic contrast-enhanced magnetic resonance imaging. Scand I Rheumatol 2014;43:109-18.

32 Axelsen MB, Poggenborg RP, Stoltenberg $M$, et al. Reliability and responsiveness of dynamic contrast-enhanced magnetic resonance imaging in rheumatoid arthritis. Scand I Rheumatol 2013:42:115-22.

33 Cootes TF, Edwards GJ, Taylor CJ. Active appearance models. IEEE Trans Pattern Anal Mach Intell 2001;23:681-5.

34 Bowes MA, Guillard G, Gill E, et al. Novel quantification of MRI provides a more sensitive outcome measure than Ramris [abstract]. Arthritis Rheumatol 2014;66: S517.

35 Østergaard M, Peterfy C, Conaghan P, et al. OMERACT Rheumatoid Arthritis Magnetic Resonance Imaging Studies. Core set of MRI acquisitions, joint pathology 
definitions, and the OMERACT RA-MRI scoring system. J Rheumatol 2003;30:1385-6.

36 Bowes MA, Vincent GR, Wolstenholme $C B$, et al. A novel method for bone area measurement provides new insights into osteoarthritis and its progression. Ann Rheum Dis 2015;74:519-25.

37 Kubassova O, Boesen M, Boyle RD, et al. Fast and robust analysis of dynamic contrast enhanced MRI datasets. Med Image Comput Comput Assist Interv 2007:10:261-9.
38 van der Heijde D. How to read radiographs according to the Sharp/van der Heijde method. I Rheumatol 2000;27:261-3.

39 Bruynesteyn $K$, Boers $M$, Kostense $P$, et al. Deciding on progression of joint damage in paired films of individual patients: smallest detectable difference or change. Ann Rheum Dis 2005;64:179-82.

40 Haavardsholm EA, Bøyesen P, Østergaard M, et al. MRI-detected bone marrow edema is a predictor of subsequent radiographic progression in early rheumatoid arthritis [abstract]. Ann Rheum Dis 2007:66(Suppl 2):94. 